\title{
Intracardiac mobile thrombus and D-dimer fragment of fibrin in patients with mitral stenosis
}

Masahiro Yasaka, Kunio Miyatake, Mayumi Mitani, Shintaro Beppu, Seiki Nagata, Takenori Yamaguchi, Teruo Omae

\begin{abstract}
Objective-To investigate the relation between intracardiac thrombus and blood coagulability in patients with mitral stenosis.

Design-Prospective study. Cross sectional echocardiography and plasma concentrations of the D-dimer fragment of fibrin were used concurrently to detect intracardiac thrombus in patients with mitral stenosis.
\end{abstract}

Setting-Department of Medicine, National Cardiovascular Centre, Osaka, Japan.

Patients-63 patients with mitral stenosis. None of them had been receiving any anticoagulants or antiplatelet agents.

Main outcome measures-Plasma concentrations of $D$-dimer in patients with a mobile intracardiac thrombus, those in patients with a non-mobile intracardiac thrombus, and those in patients without an intracardiac thrombus.

Results-A mobile intracardiac thrombus was found in 10 patients and a nonmobile thrombus in eight. The remaining 45 patients had no intracardiac thrombi. Plasma concentrations of Ddimer in the 10 patients with a mobile thrombus were all $>300 \mathrm{ng} / \mathrm{ml}$ (mean $983.3,95 \%$ confidence interval 498.9 to $1467 \cdot 7 \mathrm{ng} / \mathrm{ml}$ ) and they were significantly higher than those in the patients with a non-mobile thrombus $(226 \cdot 2,33.6$ to $418 \cdot 8$ $\mathrm{ng} / \mathrm{ml}$ ) and the patients without an intracardiac thrombus $(147 \cdot 2,110.4$ to $184 \mathrm{ng} / \mathrm{ml}$ ).

Conclusions-A high plasma concentration of D-dimer seemed to reflect a hypercoagulable intracardiac state and may be a helpful indicator of the possible presence of mobile intracardiac thrombus in patients with mitral stenosis.

Plasma concentrations of the D-dimer fragment of fibrin and fibrinopeptide $A$ have been measured to assess hypercoagulability and the secondary enhancement of fibrinolysis in patients with various disorders of the circulatory system. ${ }^{1-3}$ However, the relation between intracardiac thrombus and blood coagulability has not been fully elucidated in patients with mitral stenosis.

To investigate this relation we used cross sectional echocardiography and we measured the plasma concentrations of $\mathrm{D}$-dimer and other indices of blood coagulation concurrently in 63 patients with mitral stenosis.

\section{Patients and methods}

STUDY POPULATION

We studied 63 patients with mitral stenosis aged 53.7 (10.8) years (mean (SD)), all of whom were inpatients or outpatients at the National Cardiovascular Centre between 1 December 1987 and 31 October 1988, and 10 healthy volunteers aged $54.3(11.9)$ years. None of the patients with mitral stenosis had been taking anticoagulants, antiplatelet agents, or any other drugs that influence the haematological indices. They were all free from moderate or severe mitral regurgitation as determined by colour Doppler echocardiography. ${ }^{4}$

\section{CROSS SECTIONAL ECHOCARDIOGRAPHY}

For echocardiography we used a commercially available real time, phased array system (Toshiba SSH-60A) with a $3.75 \mathrm{MHz}$ transducer. Subjects were examined in the left lateral or supine position. The heart chambers, especially the left atrial cavity, were examined extensively by shifting, rotating, and tilting the transducer and by adjusting the gain control of the equipment whenever necessary. The criteria for the echocardiographic diagnosis of intracardiac thrombi have been reported elsewhere..$^{5} \mathrm{~A}$ thrombus was diagnosed when an echogenic mass with a clearly defined contour was seen inside the cardiac cavity, when the endocardial surface echo of the cardiac wall could be identified, and when the mass was visualised from various positions on the chest wall. The thrombus was regarded as mobile if a portion of the thrombus showed motion independent from that of the adjacent endocardium, which was either opposite in direction or freely erratic. The left atrial dimensions were measured at the same time. ${ }^{6}$

\section{COAGULATION STUDIES}

On the same day as cross sectional echocardiography we performed the following coagulation studies: haematocrit; plasma concentrations of fibrinopeptide $A$, fibrinopeptide B $\beta 15-42$, D-dimer, antithrombin III; and the 
prothrombin time and activated partial thromboplastin time. Plasma concentrations of fibrinopeptide A, fibrinopeptide $B \beta 15-42$, and $D$-dimer were measured as follows.

After discarding the first $2 \mathrm{ml}$ of blood we drew $1.6 \mathrm{ml}$ from the antecubital vein into a precooled silicone coated tube containing $1.0 \mathrm{ml}$ of inhibitor (aprotinin $10000 \mathrm{U} / \mathrm{ml}$ and heparin $500 \mathrm{U} / \mathrm{ml}$ ). The tube was immediately inverted gently several times and then centrifuged at $2000 \mathrm{~g}$ (3000 rpm) for 15 minutes at $4^{\circ} \mathrm{C}$. The supernatant was then placed in plastic tubes and stored frozen at $-20^{\circ} \mathrm{C}$. Plasma concentrations of fibrinopeptide A were determined by enzyme immunoassay (Asserachrom FPA, Diagnostica Stago, Francoville, France) and those of fibrinopeptide $B \beta 15-42$ by radioimmunoassay (Fibrinopeptide $\mathrm{B} \beta 15-42$ radioimmunoassay, IMCO Corporation, Stockholm, Sweden). ${ }^{7}$ D-dimer concentrations were measured by enzyme immunoassay (Dimertest EIA, Agen Biomedical, Brisbane, Australia) ${ }^{8}$ The prothrombin time was assessed by Quick's one-stage prothrombin time method by Thromborel $S$ (Behringwerke, Marburg, Germany) and was expressed as the international normalised ratio. ${ }^{9}$ Antithrombin III concentrations were measured by the chromogenic substrate method (Substrate: S-2238, KabiVitrum AB, Sweden). ${ }^{10}$ The observers of the cross sectional echocardiographic studies were blinded to the results of these haematological investigations.

\section{HISTORY OF EMBOLIC EVENTS}

We reviewed the history of all patients for any unequivocally documented episodes of arterial embolisation that were confirmed by angiography (cerebral and peripheral vessels), scintigraphy (kidneys), or computed tomography (brain), in addition to a history of the typical clinical signs of embolism. ${ }^{11}$

\section{STATISTICAL ANALYSIS}

Continuous data were expressed as the mean (SE). Groups were compared by analysis of variance followed by Duncan's intergroup comparison test; the $\chi^{2}$ test was also used.

\section{Results}

CROSS SECTIONAL ECHOCARDIOGRAPHY

Intracardiac thrombi were shown by echocardiography in 18 of the 63 patients (group 1). Ten of these 18 patients had mobile thrombi (fig 1), nine of which were at the left atrial appen-

Figure 1 Left parasternal short axis view (cross sectional and $M$ mode echocardiograms) from a patient with mitral stenosis. Thrombus (arrow and ${ }^{\star}$ ) at the left atrial appendage was mobile. $A O$, aorta; $L A$, left atrium. dage and the other of which was on the left atrial posterior wall. The remaining eight thrombi were non-mobile (fig 2), with seven being at the left atrial appendage and the other one being on the left atrial posterior wall. In the remaining 45 patients, there were no intracardiac thrombi (group 2).

The left atrial dimensions of the 10 healthy volunteers and groups 1 and 2 were $27 \cdot 0$ $(1.1 \mathrm{~mm}), 54.6(1.5) \mathrm{mm}$, and $52.8(1.2) \mathrm{mm}$, respectively. The left atrial dimensions of groups 1 and 2 were significantly larger than those of the controls $(p<0.01)$, but there was no significant difference between the two groups with mitral stenosis.

Forty four of the 63 patients had atrial fibrillation: $28(62 \cdot 2 \%)$ without intracardiac thrombi and $16(88.9 \%)$ in those with intracardiac thrombi. There was no significant difference in the incidence of fibrillation between the two groups ( $\chi^{2}$ test).

\section{COAGULATION STUDIES}

Plasma concentrations of fibrinopeptide A, fibrinopeptide $B / 15-42$, and D-dimer were significantly higher and those of antithrombin III were significantly lower in groups 1 and 2 than in the controls (table). Moreover, the plasma concentrations of fibrinopeptide A and D-dimer in group 1 were significantly higher than those in group 2. There were no significant differences in the haematocrit, prothrombin time, and activated partial thromboplastin time among groups 1 and 2 and the controls.

The plasma concentrations of D-dimer in the patients with mobile thrombi were all above $300 \mathrm{ng} / \mathrm{ml}(983.3(242.2) \mathrm{ng} / \mathrm{ml})$ and they were significantly higher than those in the patients with non-mobile thrombi $(226 \cdot 4(96 \cdot 3) \mathrm{ng} / \mathrm{ml}$, $\mathrm{p}<0.05$ ) (fig 3). There were no significant differences other than the D-dimer concentration between the patients with and without mobile thrombi.

\section{HISTORY OF EMBOLIC EVENTS}

Of the 63 patients, 22 had a history of confirmed arterial embolism to the brain, kidney $(\mathbf{n}=2)$, or limbs $(n=2)$ (including four patients with more than one event). All 22 patients had suffered these embolic events more than one month before this study. Nine of the 22 patients

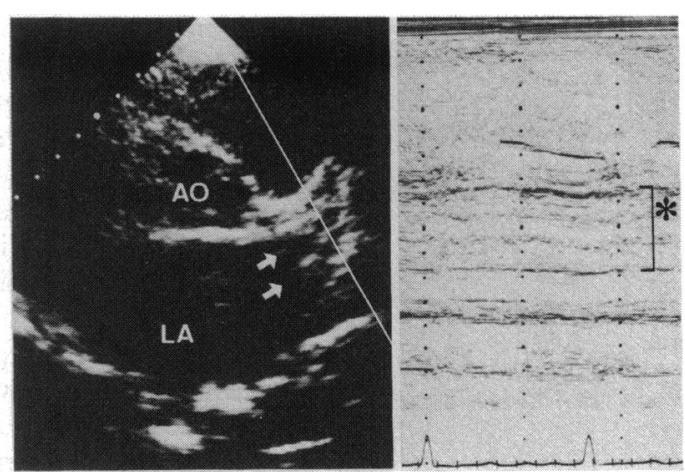

Figure 2 Left parasternal short axis view (cross sectional and $M$ mode echocardiograms) from a patient with mitral stenosis. Thrombus (arrows and ${ }^{\star}$ ) at the left atrial appendage was not mobile. AO, aorta; $L A$, left atrium. 
Haemostatic markers in patients with mitral stenosis with thrombi and without and in controls

\begin{tabular}{|c|c|c|c|}
\hline & \multirow[b]{2}{*}{$\begin{array}{l}\text { Controls } \\
(n=10)\end{array}$} & \multicolumn{2}{|c|}{ Patients with mitral stenosis } \\
\hline & & $\begin{array}{l}\text { Without thrombi } \\
(n=45)\end{array}$ & $\begin{array}{l}\text { With thrombi } \\
(n=18)\end{array}$ \\
\hline $\begin{array}{l}\text { Fibrinopeptide A (ng/ml) } \\
\text { Fibrinopeptide B } \beta 15-42(\mathrm{ng} / \mathrm{ml}) \\
\text { D-dimer (ng/ml) } \\
\text { Antithrombin III (\%) } \\
\text { Haematocrit (\%) } \\
\text { Prothrombin time (INR) } \\
\text { Activated partial thromboplastin time (s) }\end{array}$ & $\begin{array}{c}0.9(0.2) \\
2 \cdot 7(0 \cdot 3) \\
88 \cdot 5(10 \cdot 9) \\
102 \cdot 5(2 \cdot 1) \\
43 \cdot 5(0.9) \\
0.99(0.2) \\
30 \cdot 0(0 \cdot 9)\end{array}$ & $\begin{array}{c}22 \cdot 9(6 \cdot 0)^{\star} \\
7 \cdot 8(1 \cdot 5)^{\star} \\
147 \cdot 2(18 \cdot 4)^{\star} \\
91 \cdot 0(2 \cdot 1)^{\star} \\
41 \cdot 4(3 \cdot 8) \\
1 \cdot 02(0 \cdot 02) \\
32 \cdot 0(0 \cdot 5)\end{array}$ & $\begin{array}{l}50 \cdot 7(13 \cdot 0)^{\star} \dagger \\
11 \cdot 9(1 \cdot 8)^{\star} \\
646 \cdot 9(165 \cdot 2)^{\star} \ddagger \\
84 \cdot 5(3 \cdot 7)^{\star} \\
42 \cdot 8(3 \cdot 5) \\
1 \cdot 00(0 \cdot 01) \\
30 \cdot 6(0 \cdot 6)\end{array}$ \\
\hline
\end{tabular}

${ }^{\star} \mathrm{p}<0.01 v$ controls; $\nmid \mathrm{p}<0.05 v$ patients without thrombi; $\ddagger \mathrm{p}<0.01 v$ patients without

INR, International Normalised Ratio.

Figure 3 Plasma concentrations of $D$-dimer in patients with mitral stenosis with thrombi and without. Patients with a thrombus were divided into two subgroups: those with a mobile thrombus and those with a non-mobile thrombus.

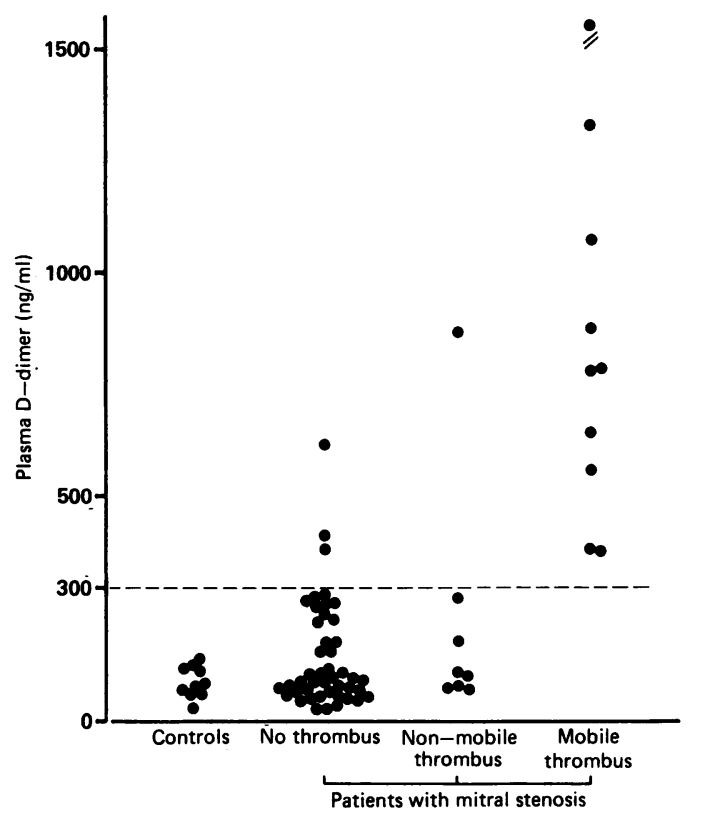

had a mobile thrombus and the other 13 did not. The remaining 41 of the 63 patients had not had either cerebral embolism or embolisation to other parts of the body.

None of the 63 patients had other diseases, such as deep vein thrombosis, renal disease, or liver disease, that could have influenced the results of the haematological investigations.

\section{Discussion}

Systemic arterial embolism is a common and important complication of mitral stenosis. ${ }^{12}$ Intracardiac thrombus is very important as a direct source of systemic embolism. Atrial fibrillation and an increase in left atrial dimensions both predispose to the development of intracardiac thrombi. ${ }^{1214}$ In our study, there were no significant differences in the incidence of atrial fibrillation or in the left atrial dimensions between groups 1 and 2 . Thus these factors are not invariably associated with intracardiac thrombi.

The plasma concentrations of fibrinopeptide A, fibrinopeptide $B \beta 15-42$, and D-dimer were significantly higher in the patients with mitral stenosis. Plasma concentrations of antithrombin III, however, were significantly lower in groups 1 and 2 than in the controls. These findings are consistent with a previous report that blood coagulability is enhanced in patients with mitral stenosis. ${ }^{15}$ Plasma concentrations of fibrinopeptide A, fibrinopeptide $B \beta 15-42$, and $D$-dimer were also higher in the patients with intracardiac thrombi than in those without. The deposition of fibrin on to an intravascular thrombus is a function of the surface area of the clot and also of the activity of the thrombotic factors associated with the clot. Hence, even small clots can result in active fibrin deposition and the production of $\mathrm{D}$-dimer, fibrinopeptide $A$, and fibrinopeptide $B \beta 15-42$.

Because blood samples were taken from an antecubital vein our result could have been influenced by thrombosis elsewhere or by emboli from the intracardiac source. However, no patients had a thrombotic disease other than the intracardiac thrombus or a past history of embolism. In all patients with a history of embolism, the interval between the onset of embolism and the study was more than a month, which is sufficient time for the emboli to have resolved spontaneously. ${ }^{16}$ Thus we do not believe that such factors are likely to have influenced the results.

D-dimer concentrations in the patients with intracardiac mobile thrombi were all above $300 \mathrm{ng} / \mathrm{ml}$, while those in most patients with non-mobile thrombi or without thrombi were below $300 \mathrm{ng} / \mathrm{ml}$. These data suggest that there was more activation of blood coagulability in the patients with mobile thrombi than in those with non-mobile thrombi, so mobile clots may be associated with more active fibrin deposition than non-mobile clots. However, four patients with non-mobile thrombi or no thrombi had D-dimer concentrations greater than $300 \mathrm{ng} /$ $\mathrm{ml}$. It is possible that they may have had a mobile thrombus in the left atrium that was smaller than the resolution of our echocardiograph, or a mobile thrombus at the tip of the left atrial appendage which is difficult to see from the transthoracic approach.

In a previous study, we reported on 30 consecutive patients with acute cardiogenic cerebral embolism who were examined by serial cross sectional echocardiography. ${ }^{17}$ In three of the patients who had mitral stenosis and a newly formed mobile thrombus at the left atrial appendage systemic embolism recurred. In the current study, nine of the 10 patients with mobile thrombus had a past history of embolism whereas none of the eight patients with non-mobile thrombus had such a history. Thus a mobile thrombus seems to be fresher and more liable to be released from the cardiac wall to cause systemic emboli. It also seems to be more likely to regrow.

In conclusion, high plasma concentrations of D-dimer are believed to reflect an intracardiac hypercoagulable state, and measurement of the D-dimer concentration may be useful as a screening method for an increased risk of intracardiac mobile thrombi in patients with mitral stenosis.

This study was supported in part by a research grant for cardiovascular disease from the Ministry of Health and Welfare (Tokyo, Japan, 1989 and 1990). 
1 Nossel HL, Ti M, Kaplan KL, Spanondis K, Soland T, Butler VP. The generation of fibrinopeptide $A$ in clinical blood samples. J Clin Invest 1976;58:1136-44.

2 Théroux P, Latour JG, Léger-Gauthier C, Lara JD. Fibrinopeptide $A$ and platelet factor levels in unstable angina pectoris. Circulation 1987;75:156-62.

3 Declerck PJ, Mombaerts P, Holvoet P, De Mol M, Collen D. Fibrinolytic response and fibrin fragment $\mathrm{D}$-dimer levels in patients with deep vein thrombosis. Thromb Haemost in patients with

4 Miyatake T, Izumi S, Okamoto $\mathrm{M}$, et al. Semiquantitative grading of severity of mitral regurgitation by real-time two-dimensional Doppler Coll Cardiol 1986;7:82-8.

5 Beppu S, Park YD, Sakakibara H, Nagata S, Nimura Y. Clinical features of intracardiac thrombosis based on echocardiographic observation. Jpn Circ J 1984;48:75-82.

6 Shan DJ, DeMaria A, Kisslo J, W eyman A. Recommendations regarding quantitation in $M$-mode echocardiography. Result of a survey of echocardiographic measurements. Circulation 1978;58:1072-83.

7 Tomura S, Oono Y, Kuriyama R, Kuriyama R, Takeuchi J. Plasma concentration of fibrinopeptide $A$ and fibronopeptide $B \beta 15-42$ in glomerulonephritis and the nephrotic syndrome. Arch Intern Med 1985;145:1033-5.

8 Rylatt DB, Blake AS, Cottis LE, et al. An immunoassay for human D dimer using monoclonal antibodies. Thromb Res 1983;31:767-78.
9 WHO expert committee on biological standardization. 28th report. WHO Tech Rep Ser 1977;610:45-51.

10 Voorthuizen HV, Kluft C. Improved assay conditions for automated antithrombin III determinations with the chromogenic substrate S-2238. Thromb Haemost 1984 52:350-3.

11 Yamaguchi T, Minematsu K, Choki J, Ikeda M. Clinical and neuroradiological analysis of thrombotic and embolic neuroradiological analysis of thrombotic

12 Cerebral embolism task force. Cardiogenic brain embolism Arch Neurol 1986;43:71-84.

13 Askey JM, Bernstein S. The management of rheumatic heart disease in relation to systemic arterial embolism. Prog Cardiovasc Dis 1960;3:220-32.

14 Daniel WG, Nellessenn U, Schröder E, et al. Left atria spontaneous echo contrast in mitral valve disease: an indicator for an increased thromboembolic risk. J Am Coll Cardiol 1988;11:1204-11.

15 Fukuda Y, Nakamura K. The incidence of thromboembolism and hemocoagulative background in patients with rheumatic heart disease. Jpn Circ J 1984;48:59-66.

16 Okada Y, Yamaguchi T, Minematsu K, et al. Hemorrhagic transformation in cerebral embolism. Stroke 1989;20: 598-603.

17 Yasaka M, Yamaguchi T, Miyashita T, et al. Predisposing factors of recurrent embolization in cardiogenic cerebral embolism. Stroke 1990;21:1000-7. 